\title{
ATYPICAL LARGE PLAQUE PARAPSORIASIS IN A YOUNG ADULT
}

Suraj Bali ${ }^{1}$, Mrityunjay Kumar Singh ${ }^{2}$, Himanshu Rana ${ }^{3}$, Mayank Singh ${ }^{4}$

\section{HOW TO CITE THIS ARTICLE:}

Suraj Bali, Mrityunjay Kumar Singh, Himanshu Rana, Mayank Singh. "Atypical Large Plaque Parapsoriasis in a Young Adult". Journal of Evolution of Medical and Dental Sciences 2015; Vol. 4, Issue 61, July 30;

Page: 10731-10734, DOI: 10.14260/jemds/2015/1548

ABSTRACT: A case of large plaque parapsoriasis with extensive skin lesions is presented for its unusual clinical features. The controversial issue of its nosological position is discussed as it has a considerable impact on the management of such cases.

KEYWORDS: Parapsoriasis, Large Plaque Parapsoriasis, Mycosis Fungoides, PUVASOL therapy.

INTRODUCTION: Parapsoriasis is a group of uncommon but not rare disorders, characterized by persistent, scaly, inflammatory eruptions. The current, generally accepted classification includes three entities: large plaque parapsoriasis (LPP), small plaque parapsoriasis (SPP), and pityriasis lichenoides.[1]

Parapsoriasis is a term coined by Brocq in 1902, as a central link of his grand design encompassing all inflammatory dermatoses, to a group of diseases characterized by the common features such as unknown etiology, chronicity, failure to respond to therapy, and lack of symptoms, particularly of pruritus.[1]

Large plaque parapsoriasis is a disease of the middle aged and older people, with a peak incidence in the fifth decade, with slight male preponderance and no racial and geographical predilection.[1]

Clinically, LPP lesions are oval or irregular shaped asymptomatic or mildly pruritic patches or very thin plaques, with most lesions bigger than $5 \mathrm{~cm}$ in diameter, and with fine wrinkles and scanty scales; telangiectasia and mottled pigmentation may also be observed. They are found mostly on the 'bathing trunk' and flexural areas, and also on extremities and upper trunk, especially breasts in women.[1] An atypical presentation with wide spread asymptomatic hypo-pigmented macule all over the body in a five year old child has been reported.[2]

Histology shows mild acanthosis, slight hyperkeratosis with spotty parakeratosis.[3] Epidermal atrophy and a band like (Lichenoid or interface reaction) multifocal infiltrate of lymphohistiocytic cells in the dermis are the histological features in the early stages of large plaque parapsoriasis. One observes an interface infiltrate, and in the more advanced lesions, definite epidermotropism. Pautrier's microabscesses are usually not found. Liquefactive degeneration of basal cells, pigmentary incontinence and dilation of blood vessels are observed in the poikilodermatous stage.

CASE REPORT: A 19 years old male presented with numerous asymptomatic hyper pigmented macules and plaques developing from the past 6years and anhidrosis all over the body, sparing head and neck, axillae and inframammary region since 4 years. To start with, an asymptomatic hyper pigmented macule was noted on the right thigh. The lesion progressively increased in size and tended to persist and spread. Similar lesions gradually developed on other body parts like trunk, limbs, axillae and groins. Pigmentation gradually increased in all these lesions. He also complained of anhydrosis over trunk, limbs, palms and soles and compensatory hyperhidrosis over head and neck, 


\section{CASE REPORT}

axillae and inframammary region. Disturbed thermoregulatory functions often led to heat intolerance in summers for which he had to pour water on his body frequently to alleviate heat. Topical steroids, urea and emollients gave temporary relief.

On examination, widespread numerous brown-black macules and thin plaques were found all over the body. Few of them showed fine scaling and few of them showed atrophy and wrinkling. The older lesions were larger with more than $5 \mathrm{~cm}$ diameter and the new smaller lesions were apparently still increasing in size. Apparently hairs were scanty over the limbs, face, eyebrows, beard and moustache. Few ichthyotic lesions noted on both the shins and periareolae. No lymphadenopathy was noted. Sensations were intact on all the lesions. General examination was unremarkable.

Histology of one of the lesion showed basket weave keratin with parakeratotic scale covered epidermis with mild intercellular edema and lymphocytic exocytosis. Underlying dermis showed mild to moderate perivascular lymphohistiocytic inflammatory infiltrate in superficial dermis. Mild melanin incontinence noted in superficial dermis. Pilosebacious units and eccrine glands were present. No atypical/abnormal cell was seen. Fite stain was negative for Acid fast bacilli. Hemogram, routine blood biochemistry, chest X-ray and urine analysis were normal. There was no atypical cell in the peripheral blood.

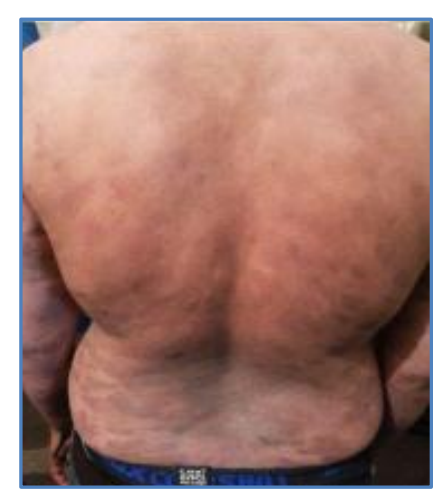

Fig. 1: Hyperpigmented macules and slightly elevated plaques over the trunk

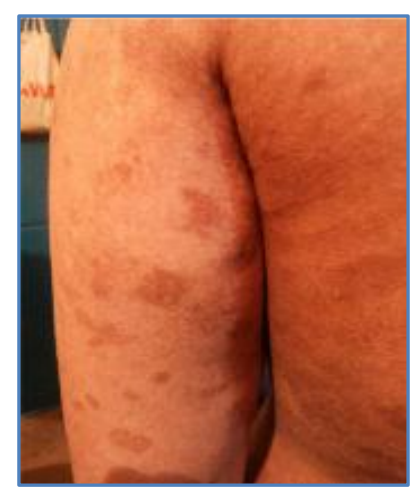

Fig. 2: Hyperpigmented macules over the arm
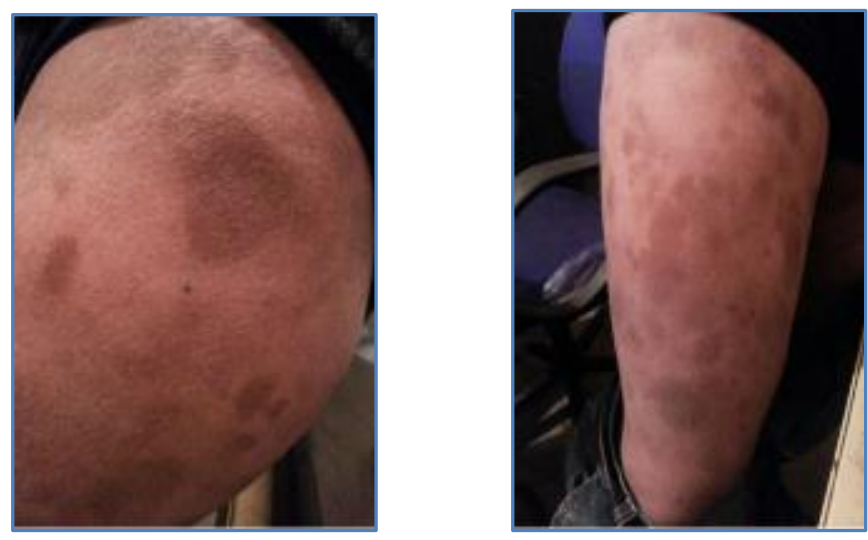

Fig. 3 \& 4: Hyper pigmented macules of variable sizes over both the thighs 
DISCUSSION: A unifying feature of parapsoriasis group of diseases is that all of them appear to be cutaneous $\mathrm{T}$ cell lymphoproliferative disorders; i.e. LPP, SPP, pityriasis lichenoides, and lymphomatoid papulosis, all have shown to be monoclonal disorders in many cases. ${ }^{[4]}$

The classification and nomenclature of parapsoriasis is plagued with controversy. A historical reason of such controversies is the fact that the word 'plaque' in French means 'patch' without thickening or induration, but in English 'plaque' refers to a circumscribed thickened or indurated area, causing confusion. The nosological position of SPP and LPP is a highly debated issue, and so is their relationship with MF.[5],[6],[7],[8] Immunohistological studies have shown similar features in LPP and early mycosis fungoides lesions, including widespread epidermal expression of human leukocyte antigen (HLADR), a predominance of CD4+T cell subsets, and frequent CD 7 antigen deficiency. There is an unresolved controversy weather LPP is precursor of MF or early MF from the outset.[9] Making a differential diagnosis between early MF and parapsoriasis often difficult at clinical and histological level.

The T cells mediating most inflammatory skin diseases, like parapsoriasis, belong to the skin associated lymphoid tissue (SALT). Mycosis fungoides have been proved to be a SALT T cell neoplasm. Studies on LPP/early MF have suggested a dominant clonal density in 1 to 10 percent, and in advanced MF a density of 50 percent or more is found. This suggests that progression from LPP through various stages of MF disease spectrum is accompanied by an increase in dominant $\mathrm{T}$ cell clonal density resulting from mutations that confer increasing growth autonomy to the neoplastic $\mathrm{T}$ cell clone. Analysis of peripheral blood has demonstrated that clonal T cells are often detectable in patients with LPP/early MF.

Thus LPP can be regarded as the clinically benign end of the mycosis fungoides disease spectrum, which may culminate in transformed large cell lymphoma at its malignant extreme. The possibility of cases presenting clinically as LPP to progress to malignant end, i.e. to MF, is about $10 \%{ }^{[10]}$ This progress often takes place over many years; hence the need of prolonged and careful follow up in all cases of LPP.

Treatment options for LPP include emollients, topical corticosteroids, topical tar, sunbathing, broad and narrow band UVB phototherapy as first line agents. Second line treatment includes topical bexarotene, imiquimod, mechlorethamine, carmustine, PUVA phototherapy and excimer laser.

To conclude, in the light of the findings of the latest studies, large plaque parapsoriasis may be considered as an early 'plaque' phase of mycosis fungoides, and this has considerable prognostic and therapeutic significance. The present case is reported for its rarity, and for the unusual clinical features, e.g., an early age of onset and associated features of disturbed thermoregulatory functions with the lesions of parapsoriasis.

\section{REFERENCES:}

1. Wood GS, Hu CH. Parapsoriasis. In: Freedberg IM, Eisen AZ, Wolff K, Austen KF, Goldsmith LA, Katz Sl, eds. Dermatology in General Medicine. 6th ed. New York: McGrawHill, 2003: 4505.

2. Das JK, Gangopadhyay AK. Large plaque parapsoriasis in a child. Indian J Dermatol. 2005; 50: 221-3.

3. Smoller BR, Bishop K, Glusac E, Kim YH, Hendrickson M. Reassessment of histologic parameters in the diagnosis of mycosis fungoides. Am J Surg Pathol. 1995; 19: 1423-30.

4. Haeffner AC, Smoller SR, Zepter K, Wood GS. Differentiation and clonality of lesional lymphocytes in small plaque parapsoriasis. Arch Dermatol 1995; 131; 3214. 
5. Ackerman AS. If small plaque (digitate) parapsoriasis is a cutaneous Tcell lymphoma, even an 'abortive' one, it must be mycosis fungoides! Arch Dermatol 1996;132: 5626.

6. Burg G, Dummer R. Small plaque (digitate) parapsoriasis is an 'abortive cutaneous $\mathrm{T}$ cell lymphoma' and is not mycosis fungoides. Arch Dermatol 1995; 131: 3368.

7. Burg G, Dummer R, Andeas H, Kemp FW, Kadin M. From inflammation to neoplasia Mycosis fungoides evolves from reactive inflammatory conditions (Lymphoid infiltrates) transforming into neoplastic plaques and tumors. Arch Dermatol 2001; 137: 94952.

8. Rubegni P, Aloe GO, Renzo MD, Pompella G, Pasqui AL, Auteri A, et al. Cytokine production profile of peripheral blood mononuclear cells in patients with large plaque parapsoriasis. Arch Dermatol 2001 ;137: 9667.

9. Whittaker SJ. Cutaneous lymphomas and lymphocytic infiltrates. In: Burns T, Breathnach S, Cox N, Griffith C, editors. Rook's textbook of dermatology. 8th ed. Singapore: Wiley-Blackwell; 2010. pp. 571-64.

10. Lambert WC, Everett MA. The nosology of parapsoriasis. J Am Acad Dermatol 1981; 5: 37395.

\section{AUTHORS:}

1. Suraj Bali

2. Mrityunjay Kumar Singh

3. Himanshu Rana

4. Mayank Singh

\section{PARTICULARS OF CONTRIBUTORS:}

1. Assistant Professor, Department of Skin \& V. D., LLMR Medical College, Meerut, Uttar Pradesh.

2. Assistant Professor, Department of Skin \& V. D., JNM Medical College, Raipur, Chhattisgarh.

3. Post Graduate Student, Department of Skin \& V. D, LLMR Medical College, Meerut, Uttar Pradesh.

FINANCIAL OR OTHER COMPETING INTERESTS: None
4. Post Graduate Student, Department of Skin \& V. D, LLMR Medical College, Meerut, Uttar Pradesh.

\section{NAME ADDRESS EMAIL ID OF THE CORRESPONDING AUTHOR:}

Dr. Mrityunjay Kumar Singh,

Plat No: F-9, Blook No. 2,

Medical College Campus,

Mekahara, Raipur-492001,

Chhattisgarh.

E-mail: mrityunjay25.ms@gmail.com

Date of Submission: 08/07/2015.

Date of Peer Review: 09/07/2015.

Date of Acceptance: 22/07/2015.

Date of Publishing: 30/07/2015. 